Article

\title{
Serving, Contemplating and Praying: Non-Postural Yoga(s), Embodiment and Spiritual Capital
}

\author{
Matteo Di Placido \\ Department of Sociology and Social Research, University of Milan-Bicocca, Milan 20126, Italy; \\ m.diplacido@campus.unimib.it
}

Received: 9 July 2018; Accepted: 6 September 2018; Published: 9 September 2018

\begin{abstract}
In this paper, I discuss the role of spiritual seekers' embodiment of karma, jnana and bhakti yoga(s) in the context of a neo-Vedantic, non-monastic ashram located in southern-Europe, an ashram I regard as an example of modern denominational yoga. Methodologically, I rely on an ex-post multi-sensory autoethnography, involving apprenticeship and full participation immersion, and I share with physical cultural studies a commitment to empirically contextualise the study of the moving body. Theoretically, I employ Shilling's theory of the body as a multi-dimensional medium for the constitution of society, enriched by other theoretical and sensitising concepts. The findings presented in this paper show that the body of the seekers/devotees can be simultaneously framed as the source of, the location for and the means to, the constitution of the social, cultural and spiritual life of the ashram. As I discuss the development, interiorisation and implementation of serving, contemplative and devotional dispositions, which together form the scheme of dispositions that shape a yogic habitus, I also consider the ties between the specific instances under study and the more general spiritual habitus. The paper ends by broadening its focus in relation to the inclusion of Asian practices and traditions into the Western landscape.
\end{abstract}

Keywords: karma yoga; jnana yoga; bhakti yoga; modern denominational yoga; body; physical culture(s); multi-sensory autoethnography; apprenticeship; full participation; neo-Vedanta

\section{Introduction}

Yoga has come to play a central role in today's consumer, popular-culture and market oriented societies [1,2] up to the point that the term yoga is automatically equated to modern postural yoga, a type of yoga primarily based on the performance of physical postures [3]. Modern postural yoga can be interpreted as a fitness regime, a stress-reduction technique, a health-maintenance practice and even as a secular religion [4-6]. Perhaps part of its success derives exactly from its malleability as well as its ability to signify something different according to the needs and attitudes of the practitioner. Although it is mostly practiced within the boundaries of yoga centres and gyms in urbanized areas [5], modern postural yoga is a crucial actor in the growing interconnected phenomena of 'New Age Spiritualities' [7,8] and 'spiritual tourism' [9-11].

Undoubtedly modern postural yoga is the most widely practiced form of modern yoga. Nonetheless it does not represent its totality. Here, I rely on De Michelis' [5] (p. 188) typology of modern yoga to account for a brief overview of the field, bearing in mind that, although this typology is a powerful heuristic tool that helps us to navigate the complex scenario of modern yoga, it is ideal-typical in a Weberian sense [12] (p. 90). In other words, this signifies that although De Michelis' typology is analytically useful in identifying core features of each one of the specific categories that comprise it, in line with Weber's own interpretation, there is no claim of a total correspondence between the ideal-types that the research constructs and the social reality that they are ought to represent. In 
fact, through closer empirical scrutiny, the lines between the different types of yoga here presented may appear more blurred and elusive than the typology is able to convey.

Swami Vivekananda's (1863-1902) Raja Yoga was the first yoga to spread and develop outside of the Indian continent and subsequently it evolved, through interactions with the Western medical and scientific discourses [13] and Western occultist and cultic milieus [5] into Modern Psychosomatic Yoga. Modern psychosomatic yoga is a yoga focused on practice, thus substantially offering an individualistic and experiential epistemology to spirituality, in line with the desires of the Western cultic milieus. Sivananda's (1887-1963) yoga and his followers are an example. Moreover, modern psychosomatic yoga evolved along two different lines: on the one hand, it expanded into Modern Postural Yoga and Modern Meditational Yoga and, on the other hand, it developed into Modern Denominational Yoga. In the case of modern postural yoga, the worldwide physical culture movement [3] (p. 80) as well as other forces, such as the prevailing Western medical and scientific discourses, played a central role in contributing to the creation of contemporary forms of yoga. Although they may vary greatly in terms of intensity, speed and complexity of the postures performed, these forms of yoga are primarily preoccupied with the performance of physical postures. Examples of this kind are Iyengar, Asthanga and Bikram styles.

Modern meditational yoga on the contrary, is more concerned with mindful practices, such as meditations of various kinds (e.g., Tantric, Vipassana, Zen etc.). Examples of this type are the early Transcendental Meditation Movement (TM) and a variety of contemporary Buddhist groups. Finally, modern denominational yoga-my concern in this paper-is characterized by a focus on neo-Guru(s) and their teaching. In general, modern denominational yoga groups have tighter organizational structures than those found in modern meditational yoga and modern postural yoga groups. This is due to them being principally constituted around the figure of a charismatic Guru and their cultic and/or sectarian character. Examples of this kind are the Society for Krishna Consciousness (ISKCON), the late Transcendental Meditation Movement (TM) [5] (p. 188) and a variety of more recent groups, such as the one discussed in this paper.

Finally, considering how the complexity and the internal articulation of the landscape of modern yoga is hardly reducible to an ordered analytical categorization without losing part of its complexity, " ... it might be more helpful to think of yogas, with a multiplicity of definitions and interpretations, rather than of a single yoga that we would seek to define and circumscribe" [15] (p. 5, emphasis in original).

Despite its widespread assimilation into popular-culture and its adaptation to the logic of consumerism, modern yoga has only recently begun to catch social scientists' attention, with the notable exception of Mircea Eliade's [16-18] early contributions. Contemporary scholarship has so far, mainly focused either on yoga history $[5,14,15,19-21]$; the transnational and transcultural character of yoga [22-24]; or yoga commodification, marketization and popularization [1,2,25,26]. Moreover, there have been a few empirical attempts that have explicitly addressed the relationship between yoga practices and the body [3,4,6,12,27-29] and embodiment [30-38]. Finally, it is relevant to mention that, although Singleton's book [3] 'Yoga Body: the origin of modern postural practice' and his later contribution [29] 'Yoga and physical culture: Transnational history and blurred discursive contexts,' map the emergence of popular, physically oriented modern yoga in relation to modern Indian physical culture, harmonial gymnastics and esoteric dance, his work is specifically focused on modern postural yoga.

In contrast, in this paper I move away from a focus on modern postural yoga and instead focus closely on the practice, teaching and lived experience of yoga in the context of a non-monastic ashram considered, in our terms, as a paradigmatic example of modern denominational yoga. I regard the practice, teaching and lived experience of the yoga(s) explored as spiritually inclined physical culture(s) which foster very specific forms of self-cultivation of and through the physical: here, the embodiment of the teachings allows the flourishing of specific dispositions oriented to the cultivation of certain prised spiritual and religious goals, which in turn contain a range of distinctive physical cultural aspects. In other words, defining physical culture(s) as "...cultural practices ... within which the moving 
physical body is central" [39] (p. 1), I intend to explore and discuss spiritual seekers' embodiment of (a) karma-yoga, or the yoga of action; (b) jnana-yoga, or the yoga of knowledge; (c) and bhakti-yoga, or the yoga of devotion, in relation to the acquisition of Spiritual Capital [40,41], namely a very specific form of cultural capital [42].

The research on the embodied experience of these less well-known forms of yoga is rather scarce, with a few notable exceptions, specifically in relation to bhakti yoga [34-38,43]. Among this body of work, as a means of example, we find ethnographic studies oriented to the exploration of the global diffusion and westernization of neo-Hindu movements [34]; and on the processes of transformation that the devotees experience in the attempt to mirror their Guru's behaviours and emulate the ethos of the movement [38]; finally, also Jack Sidnell's [44] ethnographic work on Asthanga yoga, where he relies on Foucault's late understanding of ethics to frame the physical practice of asana in terms of an ascetic practice of subjectivation is worth mentioning [44]. However, for a systematic review of the major historical, sociological and anthropological studies on modern yoga up to 2009, the reader is referred to Newcombe's seminal article, 'The Development of Modern Yoga: A Survey of the Field' [22].

In light of this, to explore and discuss how the body is experienced, understood and transformed through karma, jnana and bhakti yoga(s), might be a relevant sociological contribution not merely in relation the existing literature, or for those interested in the interaction between the sociology of the body and modern yoga but also in relation to the wider debate about the inclusion of Asian practices and traditions into the Western landscape.

The paper is structured as follows: first, I briefly sketch a few methodological notes regarding the access to, my stay in and my ongoing relationship with the ashram, then I focus on the multi-sensorial, pedagogical and fully participated nature of this ex-post autoethnographic exploration; second, I present Shilling's [45] theoretical formulation of the body as a multi-dimensional medium for the constitution of non-postural yoga(s). In this section, I intend to rely on Shilling's theory as an umbrella framework to be enriched by other theoretical and sensitising concepts, such as embodied agency, body pedagogics and habitus among others; third, in order to provide a more enhanced understanding of the yoga(s) discussed, I delineate a general overview of the landscape, structures and life at the ashram, focusing also on the figure of the charismatic Guru. In the context of this discussion I introduce the historical roots of modern forms of karma, jnana and bhakti yoga(s); fourth, drawing on the empirical evidences currently at my disposal (data collection is still ongoing as part of a PhD project on modern yoga), I unpack the manner in which the body and especially the body in motion, is at the centre of karma, bhakti and jnana yoga(s), moving from an emic to an etic perspective through the employment of the previously discussed theoretical framework; the paper ends underlining the implications of this research in relation to the inclusion of Asian practices and traditions into the Western landscape.

\section{Methodological Notes}

I have first encountered the teachings of the Guru in 2013, via online resources such as YouTube videos and I met him in person in 2015, when I attended my first seven-day silent retreat. It was back then that I entered the ashram for the first time but only for a brief period of time. Later, in 2017, I enrolled in the karma-yoga, or seva programme of the ashram and moved there, where I stayed for the following 6 months. Here I was part of the construction team, which is entitled to the construction, maintenance and restructuring of many of the structures of the ashram. When the land where the ashram rises was purchased some ten years ago, it was initially comprised of only a few ruins engulfed in lush and wild nature. The construction team, together with a small group of external contractors, contributed to the transformation of this inaccessible land into the growing and extensive architectural structure that it is today.

When I moved to the ashram, I had just submitted my application to study for a PhD in Sociology. Shortly after that, in the midst of the summer I received the news that my application was successful. At this point, I began to explore my dual role, as a seeker and a researcher, in a more conscious and systematic manner. The conscious realisation that a very fortuitous circumstance was presenting itself, 
namely the possibility of coupling an ethnographic study with my 'insider' role, was the beginning of this research project and highly influenced the methodological choices presented in the section. However, it was not until I left the field and formally began my $\mathrm{PhD}$ that I started to systematically reflect back on my experience and attempted to conceptualise it within the framework of my PhD project. The overall aim of the PhD project is, through a comparative ethnographic research design, to explore, discuss and understand yoga practitioners' lived experiences of the teachings, transmission, interiorisation and embodiment of yoga practices, ethic and philosophy within two different case studies, or communities of practice, chosen on the ground of the most-different logic. I intend to compare one postural yoga studio, located in Milan, Italy, with one ashram, located either in southern-Europe or in California (access to the sites is still under negotiation).

Most members of the ashram were aware of the fact that I was about to embark in an academic position as a researcher in the field of contemporary spirituality. Moreover, I have disclosed to some about my intention to return to the ashram to carry out more structured formal research, receiving contrasting responses. For example, different central figures of the ashram, such as the human resources team leader and other long timers, expressed their support and encouragement regarding this project. Others have been more sceptical, as is revealed by the ashram management's lack of response to my explicit (and reiterated) question on the possibility of coming back to the ashram with the formalised double role of devotee and researcher.

In other words, the empirical material and the methodological tools here discussed, are the outcome of ex-post authoethnographic reflections on my experience at the ashram. Focusing on what Sarah Wall has recently called moderate autoethnography [46], namely a form of autoethnography that keeps together evocative thick description, analysis and theorising, I attempted to use my own experiences to link them to theoretical debates and macro processes. In fact, rather than following Anderson's [47] conceptualisation of autoethnography as either evocative or analytical, I believe that the present contribution is located on a continuum between the evocative, as particularly evident in the extracts provided and the analytical, considering the theoretical and analytical focus that this work contends to discuss.

In line with the emplaced and reflexive nature of autoethnography $[46,48,49]$ I decided to reconstruct my experience at the ashram through a multi-sensory ethnographic approach [50] because it allows for a close consideration of the bodily dimension of karma, bhakti and jnana yoga(s) from the perspective of apprenticeship and full participation. In line with a long standing ethnographic tradition of participant observations, apprenticeship is seen as particularly fruitful, not only in learning about a specific practice but in learning how one learns [51] (p. 53), [49,52,53]. In other words, I relied on my role as a spiritual seeker to explore the modern denominational yoga field from the vantage point of an apprentice position. As Pink underlines [50] (p. 107).

Learning through apprenticeship requires an emplaced engagement with the practices and identities that one seeks to understand. This involves a reflexivity and self-consciousness about this learning process, establishing connections between sensory experience, specific sensory categories and philosophical, moral and other value-laden discourses (and the power relations and political processes they might be connected to) and creating relationships between these and theoretical scholarship.

Such unique emplaced engagement with the field and the phenomenon lived and studied, with a specific focus on the sensory categories of sight (e.g., the contemplation of one's own body; observing others moving, interacting, dancing and crying), touch (e.g., the feeling of the bare feet on the ground; or of the splintered wooden planks passing from hand to hand), hearing (e.g., the devotional chants and prayers; or the words of the Guru),smell (e.g., the scent of incense and sage in the main contemplative spaces) and taste (e.g., the sweet flavour of the fruit used in certain rituals carried out in the Hindu Temple of the ashram) substantially matches with physical cultural studies' sensitivity. In fact, physical cultural studies are committed to " ... contextually based understanding of the corporeal practices, discourses and subjectivities through which active bodies become organized, represented and experienced in relation to the operations of social power [54] (p. 6). In other words, through 
my position in the field as a spiritual seeker/devotee of the Guru I did not merely experience the practices promoted, lived and transmitted in the ashram as self-transformative tools but also began to reflect on the embodied and discursive features of these practices. Else said my full participation in the ashram, defined as "an unrestricted affective and relational commitment on the part of the ethnographer doing fieldwork" [55] (p. 7), forced my scholarly body [56] (p. 2) to engage, live and reflect upon the often non-rational, religious and spiritual experiences that my stay in the ashram implied and still implies to this day. However, although in line with an autoethnographic approach I rely on intimate accounts to construct my argument, which may partially reveal my personal positioning in reference to rationality, religion and spirituality, there is no intention whatsoever to advocate for the righteousness and/or the ontological validity of the experiences described. What is important to bear in mind is the fact that the experiences here addressed as spiritual and approached through the lenses of my own embodiment, are at the centre of a serious reflexive practice: this implies an epistemological break with these experiences, which in turn allows their discussion through a critical sociological perspective.

In this context, full participation is not merely a fundamental reflexive tool in the process of making sense of complex and often inexplicable experiences but it also provides the methodological ground that fully rehabilitates the body as a research tool, thanks to its sensuous engagements with the field [50]. Following this line of reasoning, I agree with Pierini's and Groissman's [56] claim that "[i]n practices in which knowledge is accessed by means of the body, ethnographers should tackle their own bodiliness in the process of knowing in the field, exploring concepts through the cultivation of cognitive and bodily skills" (p. 3).

It must be stated that full participation does not signify the complete eradication and subversion of the scholarly analytical categories, methodologies and epistemologies in doing and writing about field work. On the contrary, it suggests the employment of the researcher's own body as central to accessing, producing and evaluating rigorous ethnographic knowledge. As Halloy puts it:

full participation is in no way a panacea for all ethnographic inquiries. I understand it as both a relational attitude towards oneself and the others and a useful methodological toolbox for ethnographers interested in topics such as emotions, the senses, experience or, more broadly speaking, cultural subjectivities [55]. (p. 10)

Finally, considering the experiential, religious and transformative spiritual character of karma, bhakti and jnana yoga(s), the employment of such a reflexive, situated and bodily methodology seems not only pertinent but recommended [56]. In fact, as Palmisano [48] (p. 105) has argued, "the bodily engagement implied in autoethnography furnishes the researcher with a privileged perspective from which to examine religious experiences, especially when they become extraordinary experiences resulting from initiatic knowledge."

In the next section I provide a short theoretical discussion that I deem particularly suitable to the analysis of the actual unfolding of these yoga(s) and their bodily and embodied dimensions.

\section{Theoretical Considerations}

Shilling's $[45,57]$ theoretical project underlines the strengths and the limitations of each one of the three major contemporary approaches to the study of the body (e.g., phenomenologists, social constructionists and structuralists) and it proposes a new account able to embrace the significant advancements prompted by these lines of investigation. It is following this project, that Shilling develops a theory of the body as a multi-dimensional medium for the constitution of society, where the body is simultaneously understood as a source of, a location for and a means to the constitution of society [57].

It is important to state that although I connect Shilling's theoretical project to the work of other authors, such as Foucault and Bourdieu and traditions such as phenomenology, I employ only a selective reading and not a comprehensive rendition of these perspectives. However, I hope to show 
that the dialogue proposed is a fertile theoretical contribution to the study of bodily practices and more specifically of non-postural modern forms of yoga(s). This claim in fact seems supported by the shared commitment that these diverse authors and traditions have towards the centrality of the body and embodiment in understanding core social processes and phenomena.

Following Shilling, " ... the body constitutes a vital source for the creation of society" [45] (p. 69, emphasis in original). Here, the notions of Embodied Agency and First Person-Perspective, clearly indebted to the phenomenological tradition, substantially match Shilling's recognition of phenomenology in influencing the theorisation of the body as a source of society [45]. Furthermore, as it will be discussed below, embodied agency can be read, through a bourdieusian lens, as a crucial reference of any process of embodied capital and its plausible conversion, from, let us say, physical capital to social capital.

I define embodied agency as the individual capacity for free thought and action, where this capacity is primarily guided by proprioception (the perception of the moving body) [58] (p. 9). In other words, embodied agency presupposes an agent that perceives his or her moving body and the surrounding physical, cultural, social and symbolic environment, from a first-person perspective. Thus, embodied agency is always a matter of personal experience. In more practical terms, I intend to use the concepts of embodied agency and first-person perspective to underline the role of the devotees/seekers in actively navigating the complex landscape of motives, practices and relationships that constitute their life in the ashram.

Moving onto the conceptualisation of the body as a location for society and its influences, where " ... the body constitutes an important location on which society imprints itself and through which it is able to exercise influence and power" [45] (p. 68, emphasis in original), I introduce the concepts of Body Pedagogics and of Technologies of the Self, drawing respectively from Shilling and Mellor [59] along with Foucault [60]. The former address body pedagogics as:

the central means through which a culture seeks to transmit its main corporeal techniques, skills, dispositions and beliefs, the experiences typically associated with acquiring these attributes and the actual embodied changes resulting from this process [59] (p. 533, emphasis in original).

The latter, according to Rose [61] (p. 135) can be accounted as:

'self-steering mechanisms,' or the ways in which individuals experience, understand, judge and conduct themselves (Foucault, 1986a [60], 1986b [62], 1988 [63]). Technologies of the self take the form of the elaboration of certain techniques for the conduct of one's relation with oneself, for example requiring one to relate to oneself epistemologically (know yourself), despotically (master yourself) or in other ways (care for yourself). They are embodied in particular technical practices (confession, diary writing, group discussion, the twelve-steps programme of Alcoholics Anonymous). And they are always practiced under the actual or imagined authority of some system of truth and of some authoritative individual, whether these be theological and priestly, psychological and therapeutic or disciplinary and tutelary.

We may appreciate the substantial overlapping character between these two conceptual tools, reason for which in the context of this paper they are employed to provide a theoretical correspondence to empirically situated cases of what Shilling refers to as the role of the body as a location for the constitution of society [45] (p. 68).

Finally, and in relation to the role of the body as a means for the constitution of society, where according to Shilling "... the body constitutes a means through which individuals are attached to, or ruptured from, society" [45] (p. 68, emphasis in original), I rely on Bourdieu's [42,64-66] concepts of Habitus and Capital. According to Bourdieu's theory, habitus is the result of certain dispositions that are simultaneously shaped by practices, past events, experiences and structural influences but also shape current practices and structures. Most importantly one's own habitus, understood as a specific scheme of dispositions, once internalized, influences the individual's very perceptions of the social world [65] (p. 170). Or again, as Wacquant comments, habitus is "the way society becomes deposited in persons 
in the form of lasting dispositions, or trained capacities and structured propensities to think, feel and act in determinant ways, which then guide them" [67] (p. 316). In other words, the concept of habitus refers to the internalized dispositions, or 'truths' about him/herself and the world that an individual develops in time and in relation to his/her given social position. The habitus in turn is what allows him/her to navigate the complex reality of the social life he/she inhabits, equipped with a specific set of dispositions.

Connected to the notion of habitus we find the one of capital [42], that contrary to a Marxist understanding is defined as a form of accumulated labour composed of both material and symbolic resources. More specifically, I rely on the concept of Spiritual Capital $[40,41]$, namely a very specific form of cultural capital. Spiritual capital derives from the notion of cultural capital not only in its tripartite declination (e.g., embodied, objectified and institutionalised capital) but also its plausible conversion in other forms of capital (e.g., from spiritual capital to social capital and vice versa). As we will see discussing the empirics, it seems that the forms of capital circulating in the ashram (e.g., physical capital for the construction team, or other more diffuse forms of cultural and social and to a lesser degree economic capital) are estimated not so much in themselves but for their potential transferability to the most esteemed form of capital, namely spiritual capital.

To appreciate the analytical power of this theoretical framework it is necessary to apply it to a given empirical case. For the moment it is sufficient to underline how the body of the seeker can be simultaneously understood as: the source of his or her engagements in the ashram, with a specific focus to karma, jnana and bhakti yoga(as) as freely chosen, directly experienced and embodied by the seekers (see embodied agency and first-person perspective); the location of the Guru's dispositions and teachings and of the ashram's explicit and implicit norms, which are often the direct expression of the will of the Guru. Here the seeker and more exactly his/her body becomes the location, or the battleground for the enactment and the interiorisation of specific practices and dispositions (see body pedagogics and technologies of the self); and finally, the body of the seeker is framed as a means of his/her relationship with him/herself, the Guru and the social, cultural and spiritual life of the ashram. What is at stake here is the subtle balance between the seeker's agentic power and the acquired dispositions in negotiating with the social, cultural and spiritual life of the ashram (see habitus and spiritual capital).

In the next section I provide a short presentation of the ashram and a historical contextualisation of the yoga(s) discussed.

\section{The Ashram}

The ashram is located in a rural, hilly area in southern-Europe. It is a non-monastic community, based on non-dual, neo-Vedantic teachings. Within the property there is also a small Christian Chapel, a Hindu and a Zen Buddhist Temple. The ashram hosts people from all over the world and its official language is English. The permanent residents are about two hundred but during retreats (4-5 per year lasting from 7 to 10 days each) the ashram hosts up to thousand people. Most of the permanent residents are Europeans (mostly from UK, Italy, Spain, Portugal and France) between 25 to 45 years old of age, although there is no lack of notable exceptions, both in terms of age and country of origin. Among the other geographies represented in the ashram's socio-demographic constitution figure with a certain prominence Russia and USA. The number of Indian residents is also increasing, although the Guru is of Western origins (but he belongs to a lineage of Indian Gurus). The gender constitution of the ashram is rather balanced, while Caucasian seems to be the prevalent macro-ethnic group.

The ashram's structures and facilities are scattered all around several hills and to walk the full ashram's perimeter can take more than one hour. Moreover, these structures are, for the most part, built with wood by the ashram's construction team and/or a small group of contractors. There is a common dining area, where meals are served three times a day and consumed in complete silence; several dorms, divided by gender; several compost-toilets, located near the dorms; several contemplative spaces, ranging from the central hall where satsangs are held on a regular basis and 
where people gather mornings and evenings for collective prayers and contemplation. Among the contemplative spaces there are also a few smaller pagodas and gardens and a set of secluded small meditation platforms placed on a wooded slope of a hill; finally, there are a few offices designated to the management of the activities and initiatives of the ashram. Pictures and quotes of the Guru and other religious and spiritual leaders, mostly from Asian traditions, are found in almost every structure and room of the ashram.

To access the ashram premises is not straightforward. Aspiring residents go through a rather lengthy online application and a subsequent skype interview. Normally only those that have previously attended at least one retreat with the Guru, in presence or online, are qualified for application. There are several positions that one can apply for, according to the needs and the ongoing projects of the ashram. Usually applicants are recruited for kitchen duties (preparation and cooking); construction; land care; and a variety of other technical and administrative duties such as audio-video activities and management of the inflows of goods such as food stuff and construction material. The length of one's stay varies from a few weeks up to several months. There is also a core group of devotees that has been living in the ashram for many years, in certain cases since the ashram was established. The allocation of duties and the roles held by the devotees within the ashram seem to reproduce, at least partially, traditional gender roles: for instance, women are more likely to be assigned to the care (e.g., cleaning, organising, guarding) of the contemplative spaces and to kitchen duties, while men are more likely to engage in hard labour such as construction and land-care.

Moreover, each team has one or more persons in charge of the activities (usually a long-timer) and is organised around a pyramid like logic, with the persons in charge obviously placed on the top. They are followed by other long-timers with experience and skills in the specific activity of reference (e.g., cooking or constructing) and then by newcomers, respectively with skills and without specific qualifications. For example, a carpenter that just arrives at the ashram is usually more recognised, at least within the construction team, than a person without any manual work experience whatsoever. Another important trait to be noted, especially for the lower levels of the pyramid, is the physical strength and the will to work, which, again at least within the contours of the construction team are highly respected. In fact, as we will see below, the construction team is fully composed by male members and enacts and values a form of physical masculinity that is peculiar of building workers $[65,68]$.

After having described the ashram in terms of its socio-demographic constitution and general organisation, I will next highlight the figure of the Guru before introducing the main yoga(s) practiced in this context.

Although the Guru is a public figure, one of the many gurus and figures in contemporary neo-Vedanta, I decided to maintain his anonymity since I did not have the chance to ask for his permission about this piece of work. Following this line of reasoning I do not provide a detailed account of his life 'before enlightenment' but instead I focus on his charismatic role within the ashram and on his relationship with the devotees. However, it is worth mentioning that the Guru's own 'spiritual development' and experiences within both Christian and neo-Vedanta traditions are clearly reproduced in his teachings, in the organization of the ashram and in his relationship with the devotees. For example, let us recall the presence of a Christian Chapel among the worshipping sites of the ashram and the Guru's interchangeable usage of the terms Self, Consciousness, God or Father, which reveal a religious and spiritual socialisation across cultures.

A point of departure to understand the Gurus' relationship with his devotees is Weber's theory of charismatic leadership. According to this theory, the devotees are "[r]esting on devotion to the specific and exceptional sanctity, heroism or exemplary character of an individual person [the Guru] and of the normative patterns or order revealed or ordained by him" [69] (p. 46). Moreover, in order to appreciate the simultaneously supernatural and legitimised embodied charisma of the Guru, it is worth drawing some parallels with the issues of charismatic leadership and knowledge transmission in the context of Asian martial arts [70,71] and Western esotericism [72] (p. 400). More specifically I would like to 
rely on these lines of inquiry in two ways: first, regarding the body of the Guru (Master in the context of Asian martial arts) as an example of the embodiment of the teachings; second, in relation to the problem of transmission from Guru to student.

In the former case, the Guru is not merely seen as the unquestionable authority that prescribes a specific conduct that the students must follow for their spiritual growth [73]. The Guru and more importantly his body (e.g., the ways he moves, speaks and relates to others), are on the one hand the evidence of the effectiveness of his teachings and on the other hand the guarantee of the continuity of lineage between himself and the previous Gurus. In fact, within the body of the successful, authentic Guru, the charismatic energy, the abilities and the Spirit of its predecessor(s) are always embedded [70]. Furthermore, as Hanegraaff [72] (p. 400) echoes, in his discussion of the basic characteristic of esotericism, transmission "... refers to the transmission of knowledge from master to disciple by way of initiation. [But] It [also] includes the concept of a historical genealogy of "authentic" spiritual teachers."

In the latter case, the key aspect of transmission can be summarised with the 'feel' from the Guru's body to the disciple's body [71] (p. 69). In the context of the ashram this practice is referred as darshana, which does not have to be confused with the same term used to refer to the six Orthodox schools of Hindu philosophy and their soteriology [74]. The Guru's darshana occurs during or after satsang, when he usually spends some time embracing those disciples that happen to be closer to him. Needless to say, these embraces are not only believed and experienced as one of the manners in which the Guru transmits his knowledge to the disciples but also as thaumaturgical in character.

\section{Karma, Jnana and Bhakti Yoga(s)}

There is no warrant here to provide an exhaustive genealogy of karma, bhakti and jnana yoga(s) and neither to posit this tripartite conceptualisation as representative of the complex and variegate field of Hindu traditions. However, it is important to contextualise the ashram's practices as originating from the neo-Vedantic reinterpretation of the Bhagavadgita (III B.C.E.-I C.E.) as it took place during the Bengali Renaissance (first three quarters of the nineteen century). Moreover, I show how this model of yoga(s) was incorporated into Vivekananda's rendition, where yoga, beside functioning as an alternative to Christian missionaries' proselytism among the Bengali population, began to be framed as a substantially individualised and scientific path of self-transformation that well matched the widespread secularising and scientific concerns of the beginning of the twentieth century [3,5,75].

According to a neo-Vedantic reading, the Bhagavadgita or Song of God is considered a central text of the philosophical and religious literature of India and is part of the Indian epic the Mahabharata (IV B.C.E-IV C.E.). It is written in the form of a dialogue between the Hindu deity Krishna and the warrior Arjuna. The Bhagavadgita introduces the classical Neo-Vedantic model of the three yoga(s) (karma, jnana and bhakti) in a systematic manner. The core of karma yoga, or the yoga of action can be described, quoting directly from the Bhagavadgita [76] (Chapter 2, Verse 47) as follows: "To action alone hast thou a right and never at all to its fruits; let not the fruits of action be thy motive; neither let there be in thee any attachment to inaction." In simple words, karma yoga is presented as a form of self-less service, a form of practice, or action, where the individual is not concerned with gaining something for him or herself from his or her activities: on the contrary, the karma yogi cultivates an orientation towards just doing. This is one of the paths towards self-realisation. It is in this light that the ashram, alongside most contemporary ashrams, proposes a conspicuous and well-planned programme of karma yoga.

The second path to self-realisation presented in the Gita is jnana yoga, or the yoga of knowledge, which postulates the need to discriminate between what is real and the unreal, if one has to attain moksha, or salvation. The best-known method advocated within this path is jnana-vichara, or atma-vichara (self-inquiry), made famous by the Indian sage Ramana Maharshi (1879-1950). Self-inquiry is in fact thought to guide practitioners to self-realisation through the means of intuitive 
and constant effort in discovering the fallacy of the ' $\mathrm{I}$ ' thought or self-identity [77] and is one of the core practices also promoted in the Ashram.

The third path to salvation discussed in the Gita is bhakti yoga, or the yoga of devotion. It implies the practitioners' total commitment to the love and devotion of a specific deity, or the Guru, which is in fact considered not other from God. This tripartite model was reintroduced and adapted (with the addition of Raja yoga) in the context of the Bengali Renaissance, by figures such as Keshubchandra Sen (1838-1884), in the attempt to provide new schemes of religious and ritual life that would satisfy the increasingly secularised mentality that was spreading among the Bengali elites by the end of the nineteenth century and to counteract Christian missionaries' proselytism among the Bengali population [5]. It then appears evident how Vivekananda's original contribution has not been the theorisation of a fourth type of yoga, that as we have seen was already introduced by Sen in the Bengali context: on the contrary, his main role has been to introduce Sen's modern schemata of yoga(s) to Western audiences and to reconstruct Raja yoga as superior to all other forms: Raja yoga, given its individualistic, practice-oriented and esoteric/occultic focus was the most suitable form of yoga for Vivekananda's Western audiences [5].

The ashram discussed in this paper proposes a neo-Vedantic reading of the Bhagavadgita's model of the three yoga(s) (karma, jnana and bhakti), where work, contemplation and prayer are promoted as the real means of salvation, contrary to what are perceived to be the effortful and esoteric practices of Hatha, Raja or more in general postural and 'practice-based' forms of yoga. This 'repudiation' of physical and esoteric practices is not merely the 'taste' of neo-Vedanta but it derives from both Orthodox Hinduism and Indian popular representations of yoga and yoga practitioners [3,19]. In fact, the yogis were considered with 'disgust' and as agents of ritual pollution well before the Western colonization of India and the Bengali Renaissance [3] and were associated with promiscuous sexuality and unseemly conduct [19].

\section{Serving, Contemplating and Praying}

In what follows I introduce some empirical data and unpack the manners in which the body and especially the body in motion $[39,54]$ is at the centre of karma, jnana and bhakti yoga(s) as practiced, lived and transmitted in the ashram. In order to do so I rely on the theoretical framework previously discussed.

\subsection{Serving}

The construction team has only one full-day of rest, usually Sundays. All the remaining days, the team meets after the morning prayers and breakfast. At these meetings, the group leader assigns to each one their daily duties and then the group splits in different units in order to move on with the assigned tasks. The team is ready to serve. With no exceptions, these meetings begin with a collective group Óm, which is repeated three times and then a prayer, held by the group leader. I provide an extract from my field notes to show the dynamics of these meetings in their actual unfolding.

We hold each other hands and close our eyes. There is a moment of suspension in the silence of our breaths, gathered deep within the lungs. Somebody starts and the others follow. The sound and the vibration of the Óm pervades the small pagoda and our bodies. A few moments of silence pass by after the third Óm. Then A. speaks, softly but in a way that everybody can hear him [we are around 20 people]: "Master, that you may guide us and our work and bless the flow of the day." A few moments of suspension, again and then we slowly leave the hands of the persons next to us and bring them in the prayer position at the centre of the chest. Somebody says Amen, others stay silent. We slowly open the eyes (September 2017).

This extract is useful in underlying how the life in the ashram is organised around collective prayers and rituals. Moreover and perhaps most importantly it also shows how the working life of the ashram cannot be fully set apart from its devotional and ritualistic components. In this guise, the cultivation of 
a devotional disposition is at the centre of the ashram's culture. This element is very important since often times, the self-less nature of karma yoga, coupled with the seekers' devotion for the Guru, are used by the group leaders in order to assign some extra tasks to the members of the team, for example during satsangs or beyond the regular working day hours (from 9am to 5pm, Saturday half-day, Sunday excluded). In the following, I provide an example based on my own experience:

I am dressed all in white, excited and ready to attend satsang this evening. Walking up hill I bump into A. He looks at me. I smile. He says: "I was looking for you. I need some strong, young guy. There is a truck coming and we have to unload it." I am puzzled by his request ... Shortly after, together with a few others we are brought in the delivery place. We are not in a good mood. Satsang is starting ... I am on the back of the truck and lift, move on the side and then pass the wooden planks to the guys on the ground. These planks seem to never end. I feel my body warming up, the sweat emerging in my forearms and chest and dropping from my forehead as I work rapidly. I want to finish quickly. My hands are full of splinters and as I pass the next plank I feel we are all moving at the same rhythm, just like rowers (June 2017).

This is an example of how karma yoga activities often extend beyond the prescribed times allocated for work. This happens not only in relation to the construction team, although this team, together with land-care, is the one with the busier working schedule. Such extra demands may encounter the implicit or explicit resistance by the team members that are 'chosen' for taking care of this unplanned extra workload but the usual approach towards these gripes is to frame them as expressions of egotistic tendencies, thus providing an auspicious opportunity for further contemplation. In other words, karma yoga activities, are concurrently an example of an ethic of the postponement of gratification, teleologically oriented to the accumulation of capital [78] and of sacralisation. Ashforth and Vaidyanath [79] (p. 360) define sacralisation as a process in which, "what were once means to an end may become ends in themselves ... and the reverence vested in the ends may devolve to the means. This is the process of sacralisation, of rendering something sacred" [58] (p. 6). However, the sacralised nature of work is not merely an end in itself but it allows the cultivation of specific forms of physical, social and cultural capitals that can be readily converted. It is in this light that we may come to understand these extra demands to the seekers, not only as a legitimate form of spiritual practice but also as accumulation of capitals, where the body plays a central role.

Interestingly enough, it is possible to draw some parallels between the working culture of the ashram, in particular of the construction team and the widespread neoliberal working demands that characterise fields as different as higher education [80] and front-line service work [81], among others. In fact, whether we conceive the individuals' acceptance of extra working demands as the unavoidable outcome of poorly regulated and unbalanced power relations between management and employees, or as the individuals' choice to freely pursue his or her own objectives, whether in economic, cultural or symbolic terms, the ashram's internal dynamics and the 'outside world' seems to share a specific work ethic based on self-sacrifice [78].

In the context of karma yoga, the body emerges simultaneously as the source of, the location for and the means to, the constitution of a serving disposition: it is the source of the seekers experience of satisfaction and/or frustration in relation to work; the location of the disciplining and spiritually aligning powers of the team leaders; and finally, the means through which the individuals negotiate their positioning in the ashram. In fact, it is worth noticing that the karma yoga undertaken by the construction team, promotes a form of physical masculinity that is peculiar of building workers $[65,68]$ and that also, in the case of more established members, functions as a form of physical capital $[82,83]$ that once converted into social capital allows the person to relate with a gained authority to other seekers, whether team members or not and the ashram's organisation more at large. In other words, physical masculinity, defined on the ground of the physical capital of the workers, which in turn is constituted by a balance between workers' physical qualities such as strength, endurance, body size and finally embodied skills such as knowledge and competencies of manual work, functions as a 
crucial cultural and symbolic trait of the ashram's construction team. This seems to echo the role of physical masculinity in British builder's culture, where it is simultaneously framed as a class-bound discourse; a fundamental source of capital and status; and as a crucial backdrop of builders' personal and collective identities [68] (p. 228).

In the following note, I provide an example of the construction of physical masculinity as crucial within the internal representation of the construction team, recalling a meeting with the construction team (A) and the human resources leaders (B), which took place after a few weeks in the field:

We are sitting in a small office. Cosy and warm. The walls are made of wood, as the floor, the desk and the stools on which we are sitting. B speaks, addressing A with a big smile on her face but a firm tone in her voice: "So, how is it going?" A takes a moment, looking towards his hands, folded as usual on the top of his thighs. Then he replies: "author's first name'? [to be changed with the actual name after review] is a good, hard worker. He is always available. And strong. He is very useful for the construction team."

This extract shows that through hard work and his physical attributes, the seeker is presented with the opportunity to be accepted as a core member of the community. For instance, on the ground of my own experience and also in relation to other team members' experiences, after having repeatedly engaged in work duties beyond the regular schedule (e.g., 'he is always available'), one begins to be regarded as a core member of the team. Such an upgrade within the dynamics of the team implies more negotiating abilities regarding the work to be carried out. For example, one has the power to postpone a specific job to the following day, or to negate his availability on the ground of more urgent tasks. Else said, one's physical capital can be converted into social capital (e.g., more and better relationships within the team and the ashram) and cultural capital (e.g., recognition of one's own value and role within the team dynamics), that in turns may guarantee a smoother acquisition of spiritual capital (e.g., more free time for contemplation), the real issue at stake in the ashram. However, before concluding this section I would like to problematize the claim that spiritual capital (e.g., more free time for contemplation) is the sole and primary reason in determining individuals' actions within the context of ashram. It is in fact very common, especially among core members of the construction and land-care teams, to prioritise time for work over time for contemplation. This once again, seems to confirm a certain similarity with neoliberal working demands as unfolding in socio-economic relationship outside of the ashram. Finally, whether we decide to interpret the role of work in self-less terms or in the pursuit of a deliberate cultivation of surrender, or again simply in terms of individuals' responsibility towards the role held and the duties assigned, work is a central component of the culture of the ashram explored.

\subsection{Contemplating}

In the previous section, I explored the role of seekers' embodiment of karma yoga, underlining its entanglement with the devotional disposition promoted in the ashram. In this section I would like to primarily stress the encouraged diffused cultivation of a contemplative disposition that the seekers experience as a central component of the teachings prompted in the ashram. I employ rather personal extracts from my field notes, which I believe can help to shed light on the manners in which the seekers are instructed to unceasingly inquiry into their own nature, whether they are walking, eating, working or taking a shower.

I am walking up hill, going towards my tent. I need a good, fresh shower after a full day of hard work. I am focused in my contemplation, asking myself "Who am I? Who is 'author's first name'? [to be changed with the actual name after review] "... and suddenly, I realise that 'author's first name' [ to be changed with the actual name after review] does not exist, that is nothing but a creature of fabrication living in memory and psychological entanglements but is not here right now! And simultaneously I find myself observing my body moving by itself, as if I have nothing to do with it but observing it moving. The certitude of not being the mind or the person invades me! For a few moments I stay 
like this, out of time, out of the known, simply recognising that what or who I am transcends any boundary I previously thought or believed in. I feel like Grace, the Holy Spirit, is walking with me. I feel Ramana very close. I am grateful beyond words (June 2017).

I pour the water from the bucket onto my head. Dirty water, full of send, flows to the bottom of the shower. I notice how the water is certainly touching my body but is not touching me. I burst into a mixture of tears and laughter. I am extremely grateful (August 2017).

We can notice how in both these extracts the body is defined as an essential component of the introspective, or contemplative practice of self-inquiry. In fact, it is exactly on the background of the disidentification with the body and the mind, that the seeker is instructed, he or she can access a different layer of reality about him or herself: a reality which is the central postulate of the specific (body) pedagogics and technologies of the self taught, transmitted and lived in the ashram. Again, as previously stated, although in line with the autoethographic approach proposed, I heavily rely on intimate accounts to construct my argument, which reveals my own commitment and vision of the world regarding the issues discussed, there is no intention to advance claims of truthfulness or ontological validity of the experiences described. On the contrary, what it matters in the context of this paper, is the possibility that this first-hand, introspective accounts provide, into accessing such an elusive and difficult to grasp dimension of social life, namely spiritual experiences [48,56]. Moreover, such a situated phenomenological entry point into spiritual experiences may further help to unpack the manners in which the seekers experience the encouragement to develop a certain vision of the world through specific disciplinary devices, here conceptualizes alongside the lines of (body) pedagogics and technologies of the self. In the following extract, I provide an example of how the seekers may be socialised to the specific world view, or habitus [65] prompted in the ashram, through the guidance of more established members of the community. The context of this talk is the disclosure by the author of the experience recalled in the previous field note dated June 2017, when speaking with one of the Gurus' trusted followers under the veranda of the main office:

"Don't think it is done! Never think it is done! Keep checking your real position, moment after moment. What happened is something very beautiful. Very beautiful. Now you have to honour it." As I listen to C I am still puzzled by the experience of a few days ago. Confused. C seems to perceive my unsettlement and adds "For a while it may be like a roller coaster. In and out of personhood. You simply have to honour your seeing." (July 2017).

This extract shows how the implementation of specific body pedagogics and technologies of the self, signifies the interiorisation of the ashram's central values and encouraged dispositions (e.g., 'honour your seeing'), alongside a change in the seekers' epistemological relationship with him or herself in the light of the gained spiritual capital that derives from unceasing contemplation. This point closely resonates with what recently underlined by Jack Sidnell [44], in relation to Asthanga yoga practitioners' adherence to their practice and to the teaching of the Guru: here asana are not merely framed in terms of physical exercises but as an ascetic practice which substantially redefines the relationship of the practitioners' self with itself.

Concluding, the body is at the centre of this contemplative disposition in three simultaneous and interrelated manners: first, it is the source that allows the contemplative experience to take form and to be experienced by the seekers; second, it is the location where specific practices, or technologies of self, are employed as pedagogical tools to establish a new epistemological ground for one's relationship with oneself; third, the fruits of this contemplative disposition play out as a means through which the individual relates with others and the ashram at large. In other words, the fruits of one's introspection can be framed as a specific form of spiritual capital within the ashram, perhaps the one held in the highest regard. In fact, according to the ideological representation of the world sustained, transmitted and cultivated in the ashram, everything ranging from the ashram's relatively secluded location and its organization, to its main pedagogical tools, seems to revolve around the seekers' self-transcendence of his or her personal identity. 


\subsection{Praying}

The devotional disposition is encouraged by the daily-schedule at the ashram, which every day starts and ends with moments of collective prayer and contemplation. In the morning, at 6 a.m., the seekers meet in the main contemplative space for the recitation of a mantra which is composed by the names of the Guru and his predecessors. After this mantra, which is chanted for about half an hour and which attendance is encouraged but not mandatory, begins the aarti. The aarti refers to the Hindu religious ritual of lightening a lamp to the deities, God or/and the Guru, which is accompanied by devotional chants. The aarti usually lasts about twenty minutes, which are then followed by a forty minutes silent sitting. At times the Guru comes to sit in silence with his devotees, or to guide them through the contemplation but more often audio recorded contemplations are played. The collective meeting taking place in the evenings is composed only by the aarti and at times by the projection of some extracts from previous satsangs.

As we have seen in the case of the construction team morning meetings and of the aarti, the life in the ashram is characterised by the unfolding of continuous rituals. In fact, beside these two levels of daily worship, namely the team level and the collective level, we have to consider both the individual moments of prayer, that seekers may experience in the silence of their contemplation, for example when visiting the Chapel or the Temples and the more exceptional bhajans. Bhajans are traditional devotional songs, that within the ashram are usually played for the celebrations of specific occasions (e.g., the Guru's birthday) and at least once or twice in each retreat. In what follows I provide an extract from my field notes of one bhajan session taking place during a recent retreat.

The hall is full. On the stage, the musicians play and chant, smiling and sweeping energy all around the room. A consistent amount of people is dancing and more and more are getting up from their seats to join the others. I look around and I see a lot of people smiling, some with their eyes closed. While we chant the name of Krishna the drums accompany the pace of the dancers. The harmonium sounds irresistibly emotional. I begin to cry. My tears start to drop on the wooden floor, drawing darker spots. The legs are increasingly heavy but my heart is lighter. The music becomes faster. The hall is filled with electricity (April 2018).

This field note seems to describe a perfect empirical example of what Durkheim [84] names as collective effervescence, namely "the perceived energy field around a crowd of people that causes other people to act in a way that is not normal for them alone or in other groups" [71] (p. 69). Moreover, the ritualised, collective and ecstatic experience of the sacred that bhajans induce in the audience of seekers/devotees, is akin to Mellor's and Shilling's [85] (p. 173) notion of sensual solidarities, which is in fact based on Durkheim's collective effervescence and Simmel's analysis of sociability [86]. In the words of Mellor's and Shilling's [85] (p. 174), sensual solidarities can be described as:

consumption-oriented forms of sociality; bound up with corporeal absorption and immersion. They are based on the feelings, emotions and the effervescence which can derive from being with others (as opposed to simply discursively communicating with them).

Moreover, although Mellor and Shilling [85] (p. 174), in line with Maffesoli's [87] account of 'neo-tribes,' underline that " ... the characteristics of kinship, neighbourhood and friendship these solidarities are built on can soon disappear from their specific contexts" [85] (p. 174), in the case of the ashram explored they seem to constitute the roots of somehow more stable social, cultural, moral and spiritual relationships, although there may be the need to test this claim with the support of more robust and long-term ethnographic observations and in-depth interviews.

I would like to conclude with a few reflections on the activity of praying, broadly conceived, as it takes place within the ashram. In order to do so it may be fruitful to draw again from Durkheim's [84] 'Elementary forms of religious life,' as read through the lenses of Shilling's [45] theoretical framework, where the embodied subject, conceptualised in relation to its intentional, sensory and mobile character, 
points to the relationship that ties together basic human capacities and bodily constitution to the creation of social structures [45] (p. 10). In other words, the very constitution of the human body, which allows us to dance, sing and feel emotions, is the ground on which collective forms of spiritual experience, such the one described above, can take place. It is in this light that we can appreciate Durkheim's [84] understanding of religious collective gatherings as the foundational acts of specific social formations. In fact, religious collective gatherings and more specifically the active role of the body in devotional dances, chants and prayers is seen first, as the constitutive element, or the source, of the social, cultural and spiritual life of the ashram; second, the body is the location where the collective effervescence, or sensual solidarities, generated by these sacred gatherings are instilled into the seekers, modifying their dispositions and understanding of themselves, as well as opening further their involvement to the lifestyle promoted in the ashram, as also pointed out by Amanda Lucia in the context of her study of Amma' s devotees in the United States [38]; third, the individuals' bodily engagement within these collective ritual gatherings is itself a means through which the seeker relates with the ashram, its norms and culture and finally becomes a member. It is important to underline the passage into membership as always taking place through the incorporation of specific dispositions, weather working, contemplating or praying, that guarantee the seekers' initiation into the culture of the ashram and its teleological orientation towards self-transcendence. In other words, the seekers, through the cultivation and the embodiment of specific dispositions actively participate in the constitution of a yogic habitus and the direct or indirect acquisition of a specific form of spiritual capital.

\section{Concluding Remarks}

In this paper, I presented and discussed the role of spiritual seekers' embodiment of non-postural yoga(s), relying on Shilling's [54,57] theoretical framework enriched with a variety of other theoretical tools and reflections. In this final section, beside a short recap of the preliminary findings of this study, I would like to introduce a few considerations on how the body is experienced, understood and transformed through karma, jnana and bhakti yoga(s), especially in relation to the inclusion of Asian practices and traditions into the Western landscape.

What emerges from the interplay of the empirical evidences and the theoretical framework employed here is that the seekers' body, whether in the case of karma, jnana or bhakti yoga(s), functions simultaneously as the source of, the location for and the means to, the individuals' relationship with the ashram, its social, cultural and spiritual life. The seekers, through their (pre-existent or inculcated) desire for self-discovery, coupled with their commitment to the practices and pedagogical tools that the ashram and the Guru put at their disposal, are brought to embody a yogic habitus, that can be framed as being composed by a different balance between the serving, the contemplative and finally the devotional dispositions. This yogic habitus, is then the main means available to the seekers to negotiate and relate with the life of the ashram and its actors. In other words, it is through the development and the mastering of the yogic habitus that the seekers become the evidence of the effectiveness and supposed 'truth' of the teachings of the Guru. It is crucial to notice how this yogic habitus can be read as a particular instance of a more general spiritual habitus and in this guise it may be interesting to explore the degree of similarity and difference that the specific yogic habitus dashed in this paper, as composed of serving, contemplative and devotional dispositions, may have in relation to other yogic habitus (e.g., for example those promoted through modern postural yoga practices or in other ashrams) and other spiritual habitus as developed and promoted in other religious and spiritual fields (e.g., traditional religions, New Age Spiritualities, martial arts, etc.). In this respect, Bourdieu's [66] notion of Field may be particularly relevant in order to map a comparative overview " ... of the different kind of power or [spiritual] capital that are current in different fields" [66] (p. 724). This line of inquiry seems in fact also particularly suitable in providing an interpretation of meaningful actions (e.g., why do spiritual seekers behave the way they do?) as contextualised in practices that cultivate specific dispositions that are emerging from the available resources within specific fields of power [88]. 
Finally, it is worth reporting the centrality of spiritual capital, which can be accessed or gained either through direct experiences of the 'sacred,' as prompted by contemplation and devotion, or through the conversion of the physical, social and cultural capitals accumulated through work. Focusing on the issue of capital conversion, in fact, on the one hand the seekers/devotees, may be granted more time to contemplate and/or attend santsangs, thanks to their increased recognition within their teams and the ashram more at large and thus acquire more spiritual capital; on the other hand, spiritual capital may be acquired directly also through a relentless engagement within the working activities of the ashram. Here the seekers may approach the work as a self-less activity, in the pursuit of a deliberate cultivation of surrender, or again simply in terms of their perceived responsibility towards the role held and the duties assigned. However, to further unpack the nuances of the seekers' relationship with karma yoga activities and the reasons behind their scrupulous commitment, we may need more focused empirical explorations.

One thing can be added relying on the available data, namely the similarity between the ashram's working culture and the neoliberal working culture that characterises fields as different as higher education [80] and front-line service work [81]: these disparate contexts seem to frame the workers as the prime responsible for the delivery of expected performances, thus implying a logic of self-sacrifice as inherent in working activities. However, this does not equal to saying that there are not also important differences between the karma yoga activities carried out in the ashram and the relationships between employees and employers as unfolding within neoliberal capitalist societies. In fact, just to mention one, karma yoga activities are based on an ethic of self-less service and are not implemented to provide material personal gain, contrary to regular working positions where workers' time and skills are rewarded through economic compensation. Nevertheless, although we may claim that in the context of the ashram explored spiritual gain (e.g., spiritual capital) seems to supplant economic gain (e.g., economic capital) as the legitimising goal of working activities, the ability of individuals to promptly convert physical, social and cultural capital into spiritual capital, may be highly influenced by the already established dispositions and skills gained from the outside working environment. In order to further unpack the dynamics of this plausibly altered conversion of capital, in the light of both individuals' awareness of their own pre-existing resources and 'conversion chances' and in relation to the ashram's structure and policy of application and acceptance, more research is needed.

It is necessary at this point to underline that when discussing the relationships between Asian and Western forms of knowledge, especially in relation to the 'sacred' field of religious and spiritual traditions, there is always the risk to promote a form of implicit Orientalism. Brown and Leledaki [75] (p. 128) explain that we can locate Orientalism as the tendency to read the 'East,' as opposed to the 'West,' as intrinsically mystical, spiritual and irrational and as promoting a form of self-reflexive body-mind unity assumed to be essentially embedded in the indigenous embodied practices and philosophies of the East [89]. However, while as scholars we have to be sensitive and cautious when approaching and describing certain social realities, we also have the duty to attempt to interpret them in a manner that the voices and the values of the actors involved may be sociologically problematized and (re)presented. In this light, I can claim that a certain Orientalist tendency characterises the ashram's rendition of the yoga(s) discussed: this seems comprehensible considering the peculiar geographical and socio-demographic constitution of the ashram, which is in fact located in a southern-European country; it is mainly constituted by Europeans residents; and finally, it is structured around the figure of a non Indian-Guru. Moreover and perhaps most importantly, it is necessary to consider how a certain Orientalism is not only implicit in the geographical location and socio-demographic constitution of the ashram but represents, together with reflexive modernization and commodification, one of the main structural Western social forces through which Asian traditions are increasingly included into the West [75]. However, contrary to the shallow, or commodified Orientalism that exploits the 'cultural capital' of Asian traditions to legitimise the neoliberal ideology of late capitalism [1] (p. 25) and that further sells aspects of these ancients traditions as merely consumer goods, there seems to be also spiritually and mystically inclined reinterpretations of Asian practices, which could be considered 
as substantially adhering to certain selective interpretation of the core dictates of these traditions. Zooming in on the case of modern yoga, although sociological inquiries are still in their infancy, there seem to be several voices that report how even commodified forms of yoga, such as modern postural yoga, may be lived also as a genuine spiritual quest by their practitioners $[4,6,27,28,30-32,44,75]$. Moreover, as I attempted to show in this paper, contrary to the case of modern postural yoga where other motivations such as health, stress-reduction, fitness, educational performance, productivity and so forth, may underpin and motivate the practice in the first-place, non-postural forms of yoga(s) and more specifically karma, jnana and bhakti yoga(s), seem to be primarily motivated by religious and/or spiritual elements, such as the desire of self-realisation.

Concluding, such a privileged focus on self-realisation may be explained by the fact that the social forces of reflexive modernisation, namely the attempt to frame Asian traditions within the contours of Western scientific discourse and commodification, defined as the transformations of Asian traditions into commodities, do not seem so central in the context of the case study explored. While the teachings of the Guru and their unfolding within the contours of the ashram can surely conform to the stereotypical conceptualisation of contemporary individualised spirituality [8,90-92], they are also a proof of the existence of 'new' and evolving collective forms of relatively non-commodified religious and spiritual life. Consequently, from my understanding of the field of modern yoga and the case here discussed, it may be reasonable to conclude that the above mentioned forces of reflexive modernisation and commodification, may be more influential in the case of modern postural yoga: other forms of yoga, such as modern denominational yoga as exemplified in this article, seem to create spaces of shared religious and spiritual values and commitment, although not altogether free from Western framing discourses [33,34]. In fact, albeit a reality like the ashram explored 'forces' the seekers/devotees to a total commitment (e.g., note its residential nature versus the weekly drop-in classes that characterises modern postural yoga), it is simultaneously grounded on the imperatives of experiential epistemology and individuals' free choice that constitute the core features of contemporary spirituality [8,90-92], which in turn have to be understood as an expression of the broader focus on the individual and his or her self-responsibility that identifies late-modern, consumer societies [93-95] and neoliberal forms of governmentality $[96,97]$.

Funding: This research received no external funding.

Conflicts of Interest: The author declares no conflict of interest.

\section{References}

1. Carrette, J.R.; King, R. Selling Spirituality: The Silent Takeover of Religion; Routledge: New York, NY, USA, 2005; ISBN 0-415-30208-0.

2. Jain, A. Selling Yoga: From Counterculture to Pop Culture; Oxford University Press: New York, NY, USA, 2014; ISBN 978-0-19-939024-3.

3. Singleton, M. Yoga Body: The Origins of Modern Postural Practice; Oxford University Press: New York, NY, USA, 2010; ISBN 9780195395341.

4. Bertolo, C. Soggettività e Yoga; Unipress: Padova, Italy, 2013; ISBN 978-88-8098-312-5.

5. De Michelis, E. A History of Modern Yoga. Patañjali and Modern Esotericism, 2nd ed.; Continuum: London, Ohio, USA, 2005; ISBN 9780826487728.

6. Konecki, K.T. The Process of Becoming a Hatha-Yoga Practitioner. Qual. Sociol. Rev. 2016, 12, 6-40.

7. Campbell, C. The Easternization of the West: A Thematic Account of Cultural Change in the Modern Era, 2nd ed.; Routledge: New York, NY, USA, 2016; ISBN 978-1594512247.

8. Heelas, P. Spiritualities of Life: New Age Romanticism and Consumptive Capitalism; Blackwell Publishing: New York, NY, USA, 2008; ISBN 978-1405139380.

9. Bowers, H.; Cheer, J.M. Yoga tourism: Commodification and western embracement of eastern spiritual practice. Tour. Manag. Perspect. 2017, 24, 208-216. [CrossRef]

10. Cheer, J.M.; Belhassen, Y.; Kujawa, J. The search for spirituality in tourism: Toward a conceptual framework for spiritual tourism. Tour. Manag. Perspect. 2017, 24, 252-256. [CrossRef] 
11. Kujawa, J. Spiritual Tourism as a Quest. Tour. Manag. Perspect. 2017, 24, 193-200. [CrossRef]

12. Weber, M. The Methodology of the Social Sciences; Free Press: New York, NY, USA, 1949; ISBN 978-0029343609.

13. Alter, J. The Body between Science and Philosophy. Yoga in Modern India; Princeton University Press: Princeton, NJ, USA, 2004; ISBN 9781400843435.

14. Singleton, M.; Goldberg, E. Gurus of Modern Yoga; Oxford University Press: New York, NY, USA, 2014; ISBN 9780199938728.

15. Singleton, M.; Byrne, J. Yoga in The Modern World: Contemporary Perspectives; Routledge: New York, NY, USA, 2008; ISBN 0203894995.

16. Eliade, M. Techniques du Yoga; Gallimard: Paris, France, 1948; ISBN 2070221857.

17. Eliade, M. Patanjali et le Yoga; Seuil: Paris, France, 1962.

18. Eliade, M. Yoga: Immortality and Freedom; Princeton University Press: Princeton, NJ, USA, 1973; ISBN 0691017646.

19. White, D.G. Sinister Yogis; The University of Chicago Press: London, UK, 2009; ISBN 9780226895130.

20. White, D.G. Yoga in Practice; Princeton University Press: Princeton, NJ, USA, 2011; ISBN 9780691140865.

21. Samuel, G. The Origins of Yoga and Tantra: Indic Religions to the Thirteenth Century; Cambridge University Press: New York, NY, USA, 2008; ISBN 9780521873512.

22. Newcombe, S. The Development of Modern Yoga: A Survey of the Field. Relig. Compass 2009, 3, $986-1002$. [CrossRef]

23. Strauss, S. Adapt, Adjust, Accommodate: The Production of Yoga in a Transnational World. Hist. Anthropol. 2002, 13, 231-251. [CrossRef]

24. Strauss, S. Positioning Yoga. Balancing Acts Across Cultures; Berg: London, UK, 2005; ISBN 185973734X.

25. Askegaard, S.; Eckhardt, G.M. Glocal yoga: Re-appropriation in the Indian consumptionscape. Mark. Theory 2012, 12, 45-60. [CrossRef]

26. Coskuner-Balli, G.; Ertimur, B. Legitimation of hybrid cultural products: The case of American Yoga. Mark. Theory 2017, 17, 127-147. [CrossRef]

27. Atkinson, M. Entering scapeland: Yoga, fell and post-sport physical cultures. Sport Soc. 2010, 13, $1249-1267$. [CrossRef]

28. Irigaray, L. Una Nuova Cultura dell'Energia. Al di là di Oriente e Occidente; Bollati Boringhieri: Torino, Italy, 2011; ISBN 978-88-339-2236-2.

29. Singleton, M. Yoga and physical culture: Transnational history and blurred discursive contexts. In Routledge Handbook of Contemporary India; Jacobsen, K.A., Ed.; Routledge: Abingdon, UK, 2016; pp. 172-184, ISBN 978-0-415-73865-1.

30. Bertolo, C.; Giordan, G. Spiritualità Incorporate. Le pratiche dello Yoga; Mimesis: Milano, Italy, 2016; ISBN 978-88-5753-485-5.

31. Leledaki, A.; Brown, D.H.K. 'Physicalisation': A pedagogy of body-mind cultivation for liberation in modern yoga and meditation methods. Asian Med. 2008, 4, 303-337. [CrossRef]

32. Leledaki, A. Body-selves and health-related narratives in modern yoga and meditation methods. Qual. Res. Sport Exerc. Health 2014, 6, 278-300. [CrossRef]

33. Altglas, V. Le Nouvel Hindouisme Occidental; Editions du CNRS: Paris, France, 2005; ISBN 978-2-271-06340-3.

34. Altglas, V. The Global Diffusion and Westernization of Neo-Hindu Movements: Siddha Yoga and Sivananda Centres. Relig. South Asia 2007, 1, 217-238. [CrossRef]

35. Gold, A.G. Deep Beauty: Rajasthani Goddesses above and below the Surface. Int. J. Hindu Stud. 2008, 12, 153-179. [CrossRef]

36. McDaniel, J. The Madness of the Saints: Ecstatic Religion in Bengal; The University of Chicago Press: London, UK, 1989; ISBN 0226557235.

37. McDaniel, J. Lost Ecstasy. Its Decline and Transformation in Religion; Palgrave McMillan: Cham, Switzerland, 2018; ISBN 9783319927701.

38. Lucia, A. Reflections of Amma: Devotees in a Global Embrace; University of California Press: Berkeley, CA, USA, 2014; ISBN 9780520281141.

39. Hargreaves, J.; Vertinsky, P. Physical Culture, Power, and the Body; Routledge: New York, NY, USA, 2007; ISBN 0-415-36351-36359.

40. Verter, B. Spiritual Capital: Theorizing Religion with Bourdieu against Bourdieu. Sociol. Theory 2003, 21, 150-174. [CrossRef] 
41. Wortham, R.A.; Wortham, C.B. Spiritual Capital and the "Good Life". Sociol. Spectr. 2007, 27, 439-452. [CrossRef]

42. Bourdieu, P. The Forms of Capital. In Handbook of Theory and Research for the Sociology of Education; Richardson, J., Ed.; Greenwood Press: New York, NY, USA, 1986; pp. 241-258, ISBN 10: 0313235295.

43. Warrier, M. Hindu Selves in the Modern World: Guru Faith in the Mata Amritanandamayi Mission; RoutledgeCurzon: New York, NY, USA, 2005; ISBN 0-203-46206-8.

44. Sidnell, J. Ethical practice and techniques of the self at a yoga school in southern India. Anthropol. Today 2017, 33, 13-17. [CrossRef]

45. Shilling, C. The Body in Culture, Technology and Society; Sage: London, UK, 2005.

46. Wall, S.S. Toward a Moderate Autoethnography. Int. J. Qual. Methods 2016, 15, 1-9. [CrossRef]

47. Anderson, L. Analytic Autoethnography. J. Contemp. Ethnogr. 2006, 35, 373-395. [CrossRef]

48. Palmisano, S. Immersion in Experiencing the Sacred: Insights into the Ethnography of Religion. J. Study Relig. Exp. 2016, 2, 105-116.

49. Wacquant, L. Body and Soul: Ethnographic Notebooks of an Apprentice-Boxer; Oxford University Press: New York, NY, USA, 2004; ISBN 0195305620.

50. Pink, S. Doing Sensory Ethnography, 2nd ed.; Sage: London, UK, 2015; ISBN 978-1-4739-0595-5.

51. Downey, G. Learning Capoeira: Lessons in Cunning From Afro-Brazilian Art; Oxford University Press: Oxford, UK, 2005; ISBN 9780195176971.

52. Wacquant, L. Carnal Connections: On Embodiment, Apprenticeship, and Membership. Qual. Sociol. 2005, 28, 445-474. [CrossRef]

53. Wacquant, L. Habitus as Topic and Tool: Reflections on Becoming a Prizefighter. Qual. Res. Psychol. 2011, 8, 81-92. [CrossRef]

54. Silk, M.L.; Andrews, D.L. Toward a physical cultural studies. Sociol. Sport J. 2011, 28, 4-35. [CrossRef]

55. Halloy, A. Full Participation and Ethnographic Reflexivity: An Afro- Brazilian Case Study. J. Study Relig. Exp. 2016, 2, 7-24.

56. Pierini, E.; Groisman, A. Introduction. Fieldwork in Religion: Bodily Experience and Ethnographic Knowledge. J. Study Relig. Exp. 2016, 2, 1-6.

57. Shilling, C. The Body and Social Theory, 3rd ed.; Sage: London, UK, 2012.

58. Brown, D.H.K. Seeking spirituality through physicality in schools: Learning from 'Eastern movement forms'. Int. J. Child. Spiritual. 2013, 18, 30-45. [CrossRef]

59. Shilling, C.; Mellor, P.A. Cultures of embodied experience: Technology, religion and body pedagogics. Sociol. Rev. 2007, 55, 531-549. [CrossRef]

60. Foucault, M. The Care of the Self: The History of Sexuality Vol. 3; Pantheon Books: New York, NY, USA, 1986; ISBN 0-394-41775-5.

61. Rose, N. Identity, Genealogy, History. In Questions of Cultural Identity, 2nd ed.; Hall, S., Du Guy, P., Eds.; Sage: London, UK, 2003; pp. 128-150. ISBN 08039.

62. Foucault, M. On the genealogy of ethics: An overview of work in progress. In The Foucault Reader. An Introduction to Foucault's thought; Rabinow, P., Ed.; Penguin: Harmondsworth, UK, 1986; pp. 340-372, ISBN 10: 0140552103.

63. Foucault, M. Technologies of the self. In Technologies of the Self; Martin, L.H., Gutman, H., Hutton, P.H., Eds.; Tavistock Publications: London, UK, 1988; pp. 16-49, ISBN 0-87023-592-3.

64. Bourdieu, P. Cultural Reproduction. In Power and Ideology in Education; Karabel, J., Halsey, A.H., Eds.; Oxford University Press: New York, NY, USA, 1977; pp. 487-511, ISBN 978-0195021394.

65. Bourdieu, P. Distinction: A Social Critique of the Judgement of Taste; Routledge: London, UK, 1984; ISBN 978-84-15759-43-0.

66. Bourdieu, P. The Social Space and the Genesis of Groups. Theory Soc. 1985; 14, 723-744. [CrossRef]

67. Wacquant, L. Habitus. In International Encyclopedia of Economic Sociology; Beckert, J., Zafirovski, M., Eds.; Routledge: London, UK, 2006; pp. 315-319, ISBN 9780415286732.

68. Thiel, D. Class in construction: London building workers, dirty work and physical cultures. Br. J. Sociol. 2007, 58, 227-251. [CrossRef] [PubMed]

69. Weber, M.; Eisenstadt, S.N. Max Weber on Charisma and Institution Building; University of Chicago Press: Chicago, Il, USA, 1968; ISBN 9780226877242.

70. Brown, D.H.K. La concezione Weberiana del carisma: Il caso delle arti marziali. Relig. E Soc. 2011, 26, 42-60. 
71. Brown, D.; Jennings, G. Body lineage: Conceptualizing the transmission of traditional Asian martial arts (in the West). STAPS 2011, 32, 61-71. [CrossRef]

72. Hanegraaff, W.J. Empirical Method in the Study of Esotericism. Method Theory Study Relig. 1995, 7, 99-129. [CrossRef]

73. Foucault, M. Security, Territory, Population: Lectures at the College De France, 1977-1978; Palgrave Macmillan: New York, NY, USA, 2007; ISBN 978-1-4039-8653-5.

74. Flood, G.D. Miracles in Hinduism. In The Cambridge Companion to Miracles; Twelftree, G.H., Ed.; Cambridge University Press: Cambridge, UK, 2011; pp. 184-198. ISBN 978-0-521-89986-4.

75. Brown, D.; Leledaki, A. Eastern movement forms as body-self transforming cultural practices in the west: Towards a sociological perspective. Cult. Sociol. 2010, 4, 123-154. [CrossRef]

76. Radhakrishnan, S. The Bhagvadgita, 2nd ed.; HarperCollins India: Noida, India, 1993; ISBN 81-7223-087-7.

77. Osborne, A. Ramana Maharshi and the Path of Self-Knowledge, 3rd ed.; Sri Ramanasramam: Tiruvannamalai, India, 2006; ISBN 81-88018-11-2.

78. Weber, M. The Protestant Ethic and the Spirit of Capitalism; Oxford University Press: New York, NY, USA, 2011; ISBN 978-0199747252.

79. Ashforth, B.E.; Vaidyanath, D. Work Organizations as Secular Religions. J. Manag. Inq. 2002, 2, 359-370. [CrossRef]

80. González-Calvo, G.; Arias-Carballal, M. Effects from audit culture and neoliberalism on university teaching: An autoethnographic perspective. J. Ethnogr. Educ. 2018, 13, 413-427. [CrossRef]

81. Bélanger, J.; Edwards, P. The nature of front-line service work: Distinctive features and continuity in the employment relationship. Work Employ. Soc. 2013, 27, 433-450. [CrossRef]

82. Shilling, C. Physical Capital and Situated Action: A New Direction for Corporeal Sociology. Br. J. Sociol. Educ. 2004, 25, 473-487. [CrossRef]

83. Wacquant, L. Pugs at Work: Bodily Capital and Bodily Labour among Professional Boxers. Body Soc. 1995, 1, 65-93. [CrossRef]

84. Durkheim, E. The Elementary Forms of Religious Life; Oxford University Press: New York, NY, USA, 2001; ISBN 0192832557.

85. Mellor, P.A.; Schilling, C. Re-Forming the Body. Religion, Community and Modernity; Sage: London, UK, 1997; ISBN 9780803977228.

86. Simmel, G. The metropolis and mental life. In Georg Simmel. On Individuality and Social Forms; Levine, D., Ed.; University of Chicago Press: Chicago, Il, USA, 1971; pp. 324-339, ISBN 9790226757766.

87. Maffesoli, M. The Time of the Tribes. The Decline of Individualism in Mass Society; Sage: London, UK, 1996; ISBN 978-0803984745.

88. Wood, M.; Bunn, C. Strategy in a Religious Network: A Bourdieuian Critique of the Sociology of Spirituality. Sociology 2009, 43, 286-303. [CrossRef]

89. Said, E.W. Orientalism, 3rd ed.; Penguin: London, UK, 2003; ISBN 978-0-141-18742-6.

90. Luckmann, T. The Invisible Religion; Macmillan: New York, NY, USA, 1867; ISBN 0025767003.

91. Heelas, P.; Woodhead, L.; Seel, B.; Szerszynski, B.; Tusting, K. The Spiritual Revolution. Why Religion Is Giving Way to Spirituality; Blackwell: Oxford, UK, 2005; ISBN 1-4051-1958-6.

92. Wuthnow, R. After Heaven. Spirituality in America since the 1950s; California University Press: Berkeley, CA, USA, 1998; ISBN 978-0520222281.

93. Giddens, A. Modernity and Self-Identity: Self and Society in the Late Modern Age; Polity Press: Cambridge, UK, 1991; ISBN 9780804719445.

94. Beck, U.; Beck-Gernsheim, E. Individualization: Institutionalized Individualism and Its Social and Political Consequences; Sage: London, UK, 2002; ISBN 978-0761961123.

95. Moran, M. Identity and Capitalism; Sage: London, UK, 2015; ISBN 978-1-4462-4974-1.

96. Foucault, M. The Birth of Biopolitics: Lectures at the College De France, 1978-1979; Palgrave Macmillan: New York, NY, USA, 2008; ISBN 978-0-230-59418-0. 
97. Hache, E. La responsabilité, une technique de gouvernementalité néolibérale? Raisons Politi. 2007, 4, 49-65. [CrossRef] 